\title{
A HISTÓRIA AMBIENTAL E A PARTICIPAÇÃO DA SOCIEDADE NA CONSTRUÇÃO DE UMA TRILHA INTERPRETATIVA
}

\author{
Aline Schú ${ }^{1}$ \\ Jaime Martinez ${ }^{2}$ \\ Marcos Gerhardt ${ }^{3}$
}

Resumo: As áreas protegidas são espaços que podem proporcionar a reconexão das pessoas com a natureza. Este artigo relata a construção de uma trilha interpretativa guiada no Parque Natural Municipal João Alberto Xavier da Cruz (PNMJ) de Carazinho, Rio Grande do Sul, Brasil, com base nas memórias coletadas por meio da História Oral e empregando as referências conceituais da História Ambiental. Um teste piloto foi aplicado e a atividade passou a integrar o Programa de Uso Público da Unidade de Conservação. Ao envolver a sociedade na construção de propostas de interpretação ambiental para áreas protegidas, os sentimentos de identidade e pertencimento a estes espaços podem ser fortalecidos.

Palavras-chave: Interpretação Ambiental; Parque Natural Municipal João Alberto Xavier da Cruz; História Oral.

Abstract: Protected areas are spaces that can provide people to reconnect with nature. This article reports the construction of a guided interpretive trail in the João Alberto Xavier da Cruz Municipal Natural Park (PNMJ) of Carazinho, Rio Grande do Sul, Brazil, based on memories collected through Oral History and employing the conceptual references of Environmental History. A pilot test was applied and the activity became part of the Conservation Unit's Public Use Program. By involving society in the construction of environmental interpretation proposals for protected areas, feelings of identity and belonging to these spaces can be strengthened.

Keywords: Environmental Interpretation; João Alberto Xavier da Cruz Municipal Natural Park; Oral History.

\footnotetext{
${ }_{1}^{1}$ Universidade de Passo Fundo. E-mail: alineschu@gmail.com. http://lattes.cnpq.br/5537307282696469

${ }^{2}$ Universidade de Passo Fundo. E-mail: martinez@upf.br. http://lattes.cnpq.br/9080024619289334

3 Universidade de Passo Fundo. E-mail: marcos@gerhardt.pro.br. http://lattes.cnpq.br/7642490483610848
} 


\section{Introdução}

Áreas protegidas categorizadas como parques, são espaços de proteção integral que permitem o uso público. Segundo o artigo oitavo da Convenção sobre Diversidade Biológica, além de serem locais importantes para a conservação in situ da biodiversidade, elas permitem a visitação pública desde que se respeitem algumas regras estabelecidas no plano de manejo da unidade de conservação (BRASIL, 1992).

Neste contexto, considera-se que, se os programas de uso público forem bem planejados e executados, podem auxiliar na resolução de conflitos e envolver os visitantes em atividades de recreação, educação e interpretação ambiental. As ações previstas podem colaborar na compreensão e apreciação mais profunda dos bens naturais e culturais das áreas visitadas e estimular mudanças de comportamento, como a reorientação de hábitos, atitudes e valores (VASCONCELLOS, 1997, p. 16).

Para Medeiros (2006, p. 41), a criação de áreas protegidas pode ser considerada uma peculiar estratégia de controle do território, pois são estabelecidos limites, além de formas de uso e ocupação específicos. Nestes espaços, o controle e os critérios de utilização são, em geral, atribuídos em relação à valorização dos bens naturais existentes ou pela necessidade de resguardar biomas, ecossistemas e espécies raras ou ameaçadas de extinção. Manter porções significativas de áreas na forma de unidades de conservação continua sendo uma das estratégias de conservação mais importantes, adotada por grande número de países. Estes espaços, cada vez mais, vêm se mostrando como locais onde se estabelecem relações exitosas entre ser humano e natureza (VASCONCELLOS, 1998, p. 7).

Conforme a Lei 9.985/2000, que estabelece o Sistema Nacional de Unidades de Conservação (SNUC), os parques nacionais têm como objetivo preservar os ecossistemas de relevância ecológica e beleza cênica, e são de posse e domínio públicos, sendo que as áreas particulares em seus limites serão desapropriadas de acordo com a lei. Nestes locais é permitida a pesquisa científica, o desenvolvimento de atividades de educação e interpretação ambiental, a recreação em contato com a natureza e o turismo ecológico. De acordo com o parágrafo quarto desta mesma lei, se estes espaços forem criados pelos estados ou municípios serão chamados, respectivamente, de Parque Estadual e Parque Natural Municipal (SNUC, 2000).

As pessoas têm buscado as áreas protegidas para o lazer, praticar exercícios físicos, contemplar a paisagem, para meditação, entre outros motivos, os quais perpassam as esferas ambiental, cultural, social e espiritual e resultam em uma maior qualidade de vida. Atividades ao ar livre, como as de interpretação ambiental, têm sido procuradas por pessoas que desejam adquirir conhecimento por meio de experiências em contato com a natureza. 
A interpretação ambiental é uma atividade educativa que pretende revelar significados e inter-relações por meio da utilização de objetos originais, proporcionando o contato direto e por meio de recursos ilustrativos, não se limitando à mera comunicação de informações (TILDEN, 1977, p. 8). Conforme as Diretrizes para a Interpretação Ambiental, a utilização de diferentes técnicas pode estimular a sensibilização dos visitantes, a apreciação e o entendimento dos aspectos naturais e culturais, proporcionando vivências agradáveis e enriquecedoras. A compreensão sobre a importância da área protegida e a função como colaboradora no processo de desenvolvimento em diferentes âmbitos pode ser fortalecida (BRASIL, 2007).

Para facilitar esta compreensão, além dos aspectos biofísicos, podem ser abordados processos históricos relacionados à cultura da população do território no qual se realizam estas atividades. Por este viés, a população pode perceber que o ambiente é resultado de intrincadas relações entre o ser humano e a natureza, e compreender como as ações humanas alteram o meio ambiente.

Dentre as atividades interpretativas, as trilhas destacam-se como ferramentas utilizadas para a sensibilização acerca dos temas ambientais e a promoção da construção de conhecimentos, além de proporcionarem uma maior interação com a natureza. Conforme Martinez et al.,

o bem-estar provocado pela beleza, pela qualidade e pela integridade dos elementos que compõem a natureza conservada, cria condições propícias para o processo de aprendizagem. Em outras palavras, trata-se de um espaço pedagógico com elementos que facilitam atividades educativas, criando condições positivas de predisposição ao aprendizado. Áreas naturais podem ser consideradas como salas de aula especiais, repletas de recursos didáticos, com recursos tridimensionais coloridos, recursos diversificados de plantas, animais, paisagens, solos, pedras, recursos hídricos que nos permitem estabelecer a ligação que existe entre os elementos de suporte à vida na Terra $(2015$, p. 39).

Caso as trilhas interpretativas façam parte de um Programa de Uso Público elas podem integrar o Plano de Manejo da Unidade de Conservação, sendo oferecidas à população de maneira sistematizada. Conforme Vasconcellos (1997, p. 466), quando as trilhas são bem planejadas e implantadas, elas podem conectar os visitantes com o local, sensibilizar e aumentar a compreensão e apreciação dos bens naturais e culturais protegidos, minimizando, deste modo, as pressões negativas. Podem, também, provocar mudanças de comportamento, atraindo e engajando pessoas para as causas relacionadas à conservação. Elas ainda aumentam a satisfação do usuário, criando uma impressão positiva sobre a área protegida e a instituição 
responsável pela proteção, e podem influenciar a distribuição dos visitantes, tornando-a planejada e minimizando os impactos.

O objetivo deste estudo foi construir uma trilha interpretativa guiada com a participação da sociedade, que colaborou com testemunhos orais relacionados ao PNMJ.

As memórias, a bibliografia, os documentos e os bens naturais e culturais da área protegida serviram de subsídios para a redação da história do PNMJ, tudo fundamentado na História Ambiental e, serviu também, para a elaboração da atividade interpretativa que foi avaliada por meio de um teste piloto.

\section{Metodologia}

\section{Área de estudo}

O Parque Natural Municipal João Alberto Xavier da Cruz, (PNMJ) situase no município de Carazinho, Rio Grande do Sul, Brasil, com as coordenadas $28^{\circ} 16^{\prime} 03^{\prime \prime}$ de latitude sul e $52^{\circ} 44^{\prime} 28^{\prime \prime}$ de longitude oeste. É classificado pelo SNUC como uma área de Proteção Integral. Encontra-se em uma região com predominância de Floresta Ombrófila Mista, na qual se faz presente o pinheirobrasileiro Araucaria angustifolia (Bertol.) Kuntze (IBGE, 2012).

A área do Parque foi desapropriada em 1967, pois pertencia a Cooperativa Florestal, uma organização de madeireiros criada em 1943 e que almejava realizar a reposição do pinheiro-brasileiro. Os 206,6 hectares apresentam potencial turístico e encontram-se a cerca de $4 \mathrm{~km}$ da área urbana (Figura 1). O local é utilizado pela população, principalmente, para atividades de recreação em contato com a natureza e no desenvolvimento de atividades de educação e interpretação ambiental.

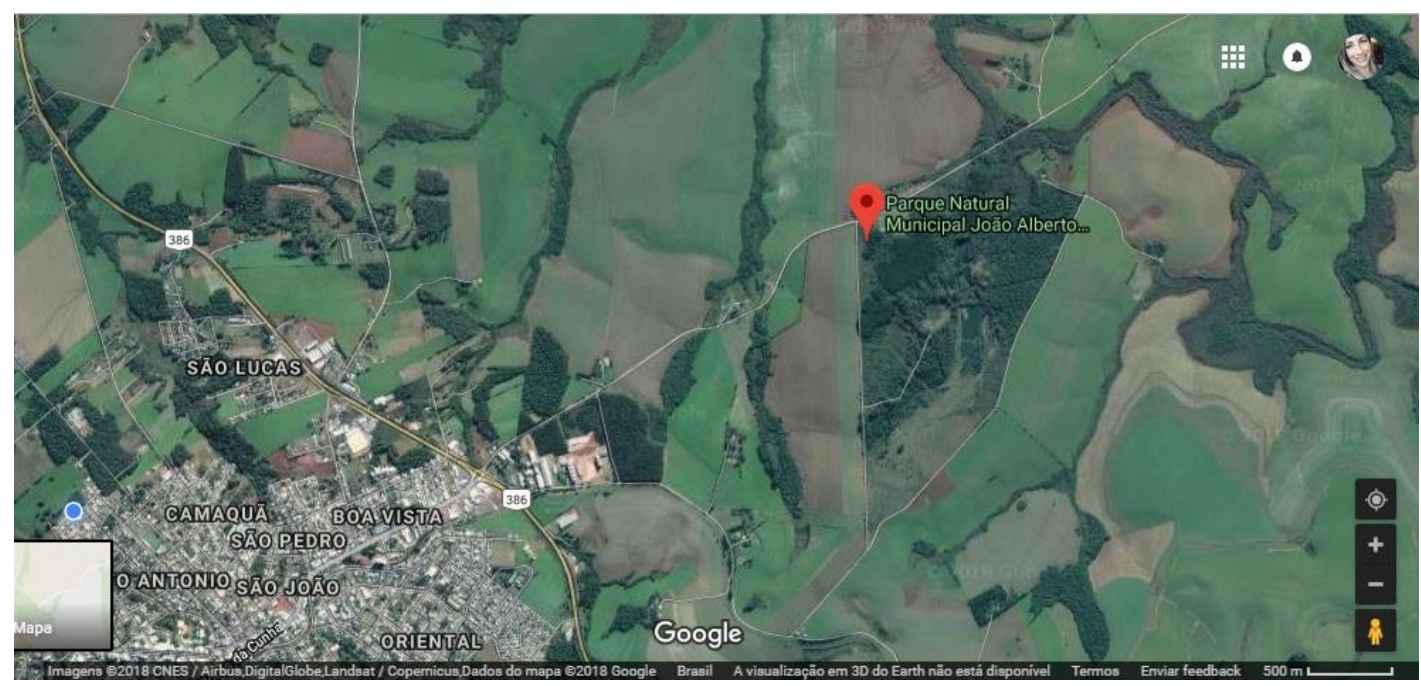

Figura 1: Localização do PNMJ em relação à área urbana de Carazinho.

Fonte: Google Maps (2019). 


\section{Trilha Interpretativa Guiada}

A trilha interpretativa guiada foi construída a partir de relatos de pessoas que viveram momentos importantes da história do PNMJ. A trilha embasou-se na História Oral e em pesquisa bibliográfica e documental, principalmente nos jornais Diário da Manhã, Jornal da Serra e Noticioso, publicados durante o período de 1930 a 2018. Nas entrevistas, os indivíduos relataram as suas relações com o PNMJ em diferentes períodos. Um teste piloto foi aplicado durante os meses de novembro de 2018 a junho de 2019. Foram organizados pequenos grupos para participar da atividade e avaliar a trilha interpretativa.

Foram planejados nove pontos interpretativos sobre a história da área protegida, evidenciando os aspectos culturais e naturais. A trilha interpretativa guiada foi denominada: "Nosso parque, nossa história: da extração madeireira à conservação ambiental". O percurso tem duração de aproximadamente 1 hora e 30minutos e apresenta grau leve de dificuldade, pois se pretende aplicá-lo ao público adulto, incluindo os idosos. Foram utilizados caminhos pré-existentes que são de fácil acesso aos visitantes.

A metodologia aplicada em cada estação do percurso seguiu as diretrizes de comunicação e estratégias da interpretação ambiental. A construção da trilha interpretativa passou por etapas que serão descritas a seguir.

\section{Etapa I - Coleta de dados junto à sociedade, em bibliografias e documentos}

Foram coletados dados a partir da História Oral e por meio de pesquisa bibliográfica e documental. A trilha temática teve como base as informações prestadas pelos participantes das entrevistas e na história da área protegida. Foram realizadas entrevistas com indivíduos que participaram de períodos significativos da história do PNMJ. Os dez entrevistados foram selecionados por meio do contato e apoio de "indivíduos-chave". Foi realizado contato prévio informal para selecionar os entrevistados. As dez entrevistas foram autorizadas pelo Comitê de Ética na Pesquisa, gravadas e posteriormente transcritas.

Os jornais pesquisados pertencem aos arquivos da Biblioteca Pública Dr. Guilherme Schultz Filho, Universidade Luterana do Brasil (ULBRA Campus Carazinho) e Associação de Amigos do Meio Ambiente (AMA).

\section{Etapa II - Conhecimento dos bens naturais do PNMJ}

Foram realizadas três expedições a campo com o intuito de identificar os principais atributos naturais e culturais da área e os pontos que se relacionavam aos relatos obtidos por meio das entrevistas. Os pontos mais expressivos foram relacionados, caracterizados, georreferenciados e fotografados. 


\section{Etapa III- Planejamento das estações da trilha}

Nesta etapa, ocorreu a construção da proposta da trilha, com a identificação do nome, objetivos e a metodologia de cada ponto (Quadro 1). Ao analisar diversos autores, Vasconcellos (1997, p. 469) reitera os seis passos básicos recomendados para o planejamento de um programa de interpretação eficaz: i) Identificação das oportunidades e necessidades (por que?); ii) Identificação do público-alvo (para quem?); iii) Identificação dos objetivos ou resultados esperados para cada público (para que?); iv) Escolha do tema ou mensagem (como?); v) Seleção das atividades, meios, métodos e técnicas (estratégias) a serem utilizados na transmissão das mensagens (como?, quem?, quando? e onde?); vi) Avaliação dos resultados e reformulação do Programa, caso necessário (controle).

Os bens naturais e culturais e os relatos obtidos por meio da História Oral serviram como subsídios, juntamente com as referências conceituais da história ambiental, para o planejamento da trilha.

\section{Etapa IV - Teste piloto da trilha}

A trilha foi direcionada ao público adulto. Um grupo heterogêneo foi convidado para participar do teste piloto, a fim de verificar se os objetivos e metodologias estavam de acordo com a proposta de cada ponto. Participaram da trilha grupos de idosos, professores, gestores e sociedade em geral.

\section{Etapa $\boldsymbol{V}$ - Avaliação da trilha}

Foram aplicados questionários após a realização da trilha interpretativa guiada, para posterior análise das percepções sobre a atividade e caracterização dos visitantes (Anexo A).

\section{Resultados e discussão}

\section{A História Ambiental e Oral como subsídios para construção da trilha}

Anteriormente a este estudo, não havia uma história do PNMJ. Por meio da pesquisa realizada, levantou-se informações relativas à área protegida, as quais serviram de base para uma dissertação de mestrado e para a construção da trilha interpretativa.

Abranger as sociedades humanas e também reconhecer a historicidade do meio natural faz parte das atribuições da História Ambiental como ciência social. O desafio é "construir uma leitura aberta e interativa da relação de ambos" (PÁDUA, 2010, p. 97).

Conforme as Diretrizes para Interpretação Ambiental em áreas protegidas é necessário envolver a sociedade local no processo de construção dos instrumentos interpretativos (BRASIL, 2007). Utilizar a História Oral como 
metodologia para a construção de uma história e elaboração de uma trilha interpretativa, pode valorizar os sujeitos e estimular o envolvimento da sociedade na formulação de propostas de interpretação ambiental para áreas protegidas. Por meio da participação, o sentimento de pertencimento e identidade em relação a estes espaços é incentivado, os indivíduos tendem a se sentir valorizados e a apropriarem-se dos espaços públicos. Ao compartilhar as vivências por meio da história oral, os cidadãos podem contribuir para a preservação da memória local e do patrimônio ambiental. Durante a coleta de dados, alguns dos entrevistados desta pesquisa demonstraram satisfação e orgulho por poderem compartilhar memórias das suas vivências e colaborar com as informações na elaboração do planejamento.

Neste sentido, para Gerhardt e Nodari (2016, p. 67),

existe um patrimônio ambiental que resulta de uma combinação complexa de natureza e cultura. Ele é, ao mesmo tempo, cultural e natural, pois são duas faces da mesma realidade. A biodiversidade e a diversidade cultural são essenciais $\mathrm{e}$ inerentes ao patrimônio ambiental. A conservação deste patrimônio depende, é claro, da atuação do Estado, mas depende também das pessoas o reconhecerem como seu, pois elas elaboram sua identidade coletiva a partir dele e podem considerá-lo uma herança a ser conservada para que prossiga existindo.

Segundo Rovai (2013, p. 12), quando os entrevistados falam sobre o ambiente circundante, fica evidente a relação intrínseca entre este meio e os narradores. Natureza e cultura não são antagônicas, uma vez que se integram e se influenciam dialeticamente. Esta relação é contínua e reinventada a cada geração, já que ambas são dinâmicas e vivas.

\section{As percepções dos entrevistados sobre o PNMJ}

Os entrevistados nesta pesquisa foram indagados sobre as suas percepções sobre o PNMJ, a fim de verificar quais os significados que eles atribuem ao local (Anexo B).

Prestes, N. P. (2019), salientou que o PNMJ tem relevância, pois apesar de não ser uma área grande, é extremamente significativa para o município. Além da beleza cênica, detém potencial turístico e didático, apresenta possibilidades para pesquisa, atividades de Educação Ambiental e em contato com a natureza. O município possui poucas áreas verdes, destacando as praças e o "Mato do Sabiá", os quais nem sempre cumprem com as suas finalidades. Falta segurança e um olhar atencioso para estes locais. Salientou o envolvimento da sociedade em atividades relacionadas ao PNMJ e as manifestações culturais na forma de músicas, poesias, pinturas entre outras. $\mathrm{O}$ parque é um local para sociabilização e prática de atividades físicas, e deste modo, proporciona bem-estar. Para ela, o parque foi uma escola, pois 
possibilitou a vivência de momentos relacionados a atividades de pesquisa e conservação da natureza. São poucos os municípios que possuem áreas protegidas públicas. A seu ver, o PNMJ deve ser melhor aproveitado e divulgado.

Para Suckau, V. A. (2019), outra entrevistada, o parque tem importância emocional e ecológica. Deve ser mais valorizado e divulgado, pois é uma área magnífica. Poucos lugares possuem uma área pública criada por iniciativa municipal. O parque deve ser um local de fácil acesso à população e a natureza deve ser conservada. Destacou a necessidade de refazer o plano de manejo.

Conforme Vidal, P. G. (2019), ex-funcionário do PNMJ, a área é o local de lazer da população pobre e por isso, deve estar sempre bem organizado.

Lopes, M.R. (2019), professora aposentada e filha de Olívio Otto, que foi o responsável pela gestão da área na década de 1970, vê o parque como um lugar de encontro e de lazer. Apresenta, para ela, valor sentimental, pois conviveu muito com a família nele. O local proporciona contato com a natureza, principalmente para as crianças que, muitas vezes, vivem afastadas de áreas verdes.

Kussler, A. L. (2019), gestor do PNMJ, relatou que tem atribuições de área de lazer e conservação da natureza. Para ele o parque é um local diferente pela diversidade de ambientes e é espaço para recarregar as energias em contato com a natureza. Faz parte do patrimônio do município, por isto deve ser resguardado.

Hüning, C. (2019), ex-diretora do Departamento de Meio Ambiente, vê o local como um ambiente conservado, onde a população pode usufruir de uma paisagem diversa, constituída por floresta nativa e exótica. Apresenta possibilidades para a pesquisa científica e como área de lazer.

Para Luz, S. R. D. (2019), professora aposentada e integrante da AMA, o parque é uma área de conservação da natureza e deve ser valorizado por toda a população, não apenas pelos ambientalistas. O local tem potencial para pesquisa, lazer, turismo e educação. De acordo com Toledo, S. (2019), professora aposentada e integrante da AMA, o PNMJ poderia ser melhor utilizado pelas escolas para estudos, e tem, também, potencial para o turismo ecológico, o que contribuiria economicamente para o município.

Conforme o Artigo 11 do SNUC, os parques têm o objetivo de preservar os ecossistemas naturais de importância ecológica e beleza cênica. Nestes locais podem ser realizadas atividades de pesquisa científica, educação e interpretação ambiental, recreação em contato com a natureza e turismo ecológico (SNUC, 2000). Verifica-se que as percepções dos entrevistados estão de acordo com as atribuições previstas no SNUC para áreas desta categoria, o que pode ser relacionado ao histórico de atuação dos entrevistados nas áreas de conservação da natureza e educação. 


\section{A proposta construída}

Após a análise dos relatos obtidos por meio da história oral e a comparação com os resultados da pesquisa relacionados à história do PNMJ, a trilha ficou constituída conforme o Quadro 1.

Quadro 1: Nome, descrição, objetivos e metodologias das nove estações interpretativas da Trilha: "Nosso parque, nossa história: da extração madeireira à conservação ambiental".

\begin{tabular}{|c|c|c|c|c|c|}
\hline Ponto & Descrição & Nome & Objetivo & Metodologia & $\begin{array}{l}\text { Subsídios } \\
\text { utilizados }\end{array}$ \\
\hline 1 & $\begin{array}{l}\text { Pórtico de } \\
\text { entrada }\end{array}$ & $\begin{array}{c}\text { Um convite } \\
\text { para voltar } \\
\text { no tempo }\end{array}$ & $\begin{array}{c}\text { Informar os } \\
\text { participantes } \\
\text { sobre a } \\
\text { história da } \\
\text { criação do } \\
\text { Parque e } \\
\text { sobre as } \\
\text { regras básicas } \\
\text { de conduta na } \\
\text { trilha } \\
\text { interpretativa } \\
\text { guiada. }\end{array}$ & $\begin{array}{c}\text { Apresentação do guia. Os } \\
\text { participantes são convidados a } \\
\text { compartilhar as suas } \\
\text { memórias em relação à área } \\
\text { protegida. Informar que a trilha } \\
\text { é um momento de troca, no } \\
\text { qual todos podem contribuir a } \\
\text { qualquer momento do } \\
\text { percurso. Explicar que a trilha } \\
\text { foi construída com a } \\
\text { participação da sociedade, a } \\
\text { partir da história oral. Efetuar } \\
\text { um breve relato referente à } \\
\text { criação do PNMJ e à } \\
\text { transformação em área } \\
\text { protegida. Neste ponto, que } \\
\text { marca o início da trilha, são } \\
\text { fornecidas informações sobre } \\
\text { a conduta dos visitantes na } \\
\text { trilha interpretativa guiada. }\end{array}$ & $\begin{array}{l}\text { Pesquisa: } \\
\text { Jornais, } \\
\text { legislação, } \\
\text { história oral, } \\
\text { documentos e } \\
\text { bibliografia. } \\
\\
\text { Bens naturais e } \\
\text { culturais e } \\
\text { recursos } \\
\text { didáticos: pórtico } \\
\text { de entrada do } \\
\text { Parque, placas } \\
\text { informativas com } \\
\text { regras para } \\
\text { visitação, folheto } \\
\text { informativo e } \\
\text { mapa. }\end{array}$ \\
\hline 2 & $\begin{array}{c}\text { Área com } \\
\text { vegetação } \\
\text { em } \\
\text { diferentes } \\
\text { estágios } \\
\text { de } \\
\text { sucessão }\end{array}$ & $\begin{array}{c}\text { "Floresta } \\
\text { em } \\
\text { Formação" }\end{array}$ & $\begin{array}{c}\text { Valorizar os } \\
\text { esforços da } \\
\text { comunidade } \\
\text { escolar e } \\
\text { idosos em } \\
\text { relação ao } \\
\text { PNMJ. }\end{array}$ & $\begin{array}{l}\text { Ao lado da placa que diz } \\
\text { "Floresta em Formação", } \\
\text { perguntar aos participantes se } \\
\text { eles sabem o que é uma } \\
\text { floresta em formação. Mostrar } \\
\text { os diferentes estágios em que } \\
\text { a vegetação do local se } \\
\text { encontra e descrever como se } \\
\text { deu a participação da } \\
\text { comunidade escolar e dos } \\
\text { grupos de idosos no plantio de } \\
\text { árvores e nas atividades } \\
\text { educativas desenvolvidas na } \\
\text { UC, principalmente na década } \\
\text { de } 1980 \text {. Abordar brevemente } \\
\text { o problema das queimadas } \\
\text { que ocorriam na área de } \\
\text { regeneração. }\end{array}$ & $\begin{array}{c}\text { Pesquisa: História } \\
\text { oral, jornais, } \\
\text { bibliografia e } \\
\text { regulamentos das } \\
\text { Ecogincanas I e } \\
\text { II. } \\
\\
\text { Bens naturais e } \\
\text { culturais e } \\
\text { recursos } \\
\text { didáticos: Placa } \\
\text { "Floresta em } \\
\text { formação" } \\
\text { colocada por } \\
\text { estudantes, } \\
\text { vegetação em } \\
\text { diferentes } \\
\text { estágios, folheto } \\
\text { informativo e } \\
\text { mapa. }\end{array}$ \\
\hline
\end{tabular}

Continua...

Revbea, São Paulo, V. 15, № 5: 01-19, 2020. 


\begin{tabular}{|c|c|c|c|c|c|}
\hline Ponto & Descrição & Nome & Objetivo & Metodologia & $\begin{array}{l}\text { Subsídios } \\
\text { utilizados }\end{array}$ \\
\hline 3 & $\begin{array}{l}\text { Ponto } \\
\text { turístico } \\
\text { das Três } \\
\text { Cruzes }\end{array}$ & $\begin{array}{l}\text { A árvore } \\
\text { sagrada }\end{array}$ & $\begin{array}{l}\text { Proporcionar } \\
\text { um momento } \\
\text { de } \\
\text { espiritualidade } \\
\text { e reflexão, de } \\
\text { reconexão } \\
\text { com a } \\
\text { natureza. } \\
\text { Salientar a } \\
\text { importância } \\
\text { econômica, } \\
\text { cultural, social } \\
\text { e ambiental da } \\
\text { araucária e } \\
\text { relatar a } \\
\text { origem do } \\
\text { Ponto das } \\
\text { Três Cruzes. }\end{array}$ & $\begin{array}{l}\text { Fazer um círculo e questionar } \\
\text { sobre o porquê de a araucária } \\
\text { ser considerada uma árvore } \\
\text { sagrada, principalmente para } \\
\text { grupos da população do sul do } \\
\text { Brasil. Pedir aos participantes } \\
\text { para que compartilhem as } \\
\text { suas memórias relacionadas a } \\
\text { esta planta. Solicitar para que } \\
\text { deem as mãos e fechem os } \\
\text { olhos por alguns instantes, } \\
\text { com o intuito de sentir o ar } \\
\text { entrando e saindo dos } \\
\text { pulmões, sentindo a } \\
\text { conexidade com o meio, } \\
\text { através da troca de átomos. } \\
\text { Falar sobre a importância da } \\
\text { araucária nas esferas } \\
\text { ambiental, cultural, econômica } \\
\text { e social, para os povos } \\
\text { tradicionais e demais } \\
\text { populações. Por fim, relatar } \\
\text { que o ponto foi idealizado por } \\
\text { Olívio Otto, como local para } \\
\text { meditação e oração. }\end{array}$ & $\begin{array}{c}\text { Pesquisa: História } \\
\text { oral e bibliografia. } \\
\text { Bens naturais e } \\
\text { culturais e } \\
\text { recursos } \\
\text { didáticos: } \\
\text { Plantio de } \\
\text { araucárias e as } \\
\text { três cruzes, } \\
\text { folheto } \\
\text { informativo e } \\
\text { mapa. }\end{array}$ \\
\hline 4 & $\begin{array}{l}\text { Área com } \\
\text { frutíferas } \\
\text { plantadas }\end{array}$ & $\begin{array}{l}\text { O pomar } \\
\text { do "Seu" } \\
\text { Olívio }\end{array}$ & $\begin{array}{l}\text { Informar sobre } \\
\text { a atuação de } \\
\text { Olívio Otto } \\
\text { como } \\
\text { encarregado } \\
\text { do PNMJ. }\end{array}$ & $\begin{array}{l}\text { Entrar na área em que Olívio } \\
\text { Otto efetuou o plantio de } \\
\text { árvores frutíferas nativas e } \\
\text { exóticas. Pedir para que os } \\
\text { participantes observem o } \\
\text { alinhamento das árvores, o } \\
\text { qual evidencia a intervenção } \\
\text { humana. Falar sobre Olívio } \\
\text { Otto e sua influência na área } \\
\text { protegida e como cidadão } \\
\text { atuante no município. }\end{array}$ & $\begin{array}{l}\text { Pesquisa: História } \\
\text { oral e jornais. } \\
\text { Bens naturais e } \\
\text { culturais e } \\
\text { recursos } \\
\text { didáticos: } \\
\text { Plantio de árvores } \\
\text { frutíferas nativas } \\
\text { e exóticas, folheto } \\
\text { informativo e } \\
\text { mapa. }\end{array}$ \\
\hline 5 & $\begin{array}{l}\text { Plantio de } \\
\text { araucárias }\end{array}$ & $\begin{array}{l}\text { De pinhão } \\
\text { em pinhão. }\end{array}$ & $\begin{array}{l}\text { Descrever a } \\
\text { história } \\
\text { ambiental do } \\
\text { município nas } \\
\text { décadas de } \\
1920 \text { a } 1940 \text { e } \\
\text { a relação da } \\
\text { extração } \\
\text { madeireira } \\
\text { com a criação } \\
\text { do Parque. }\end{array}$ & $\begin{array}{c}\text { Pedir para que os } \\
\text { participantes observem as } \\
\text { araucárias e que digam o que } \\
\text { há de estranho com elas. } \\
\text { Espera-se que percebam o } \\
\text { plantio próximo e que as } \\
\text { árvores estão pouco } \\
\text { desenvolvidas. Falar sobre a } \\
\text { biologia da araucária, relatar a } \\
\text { história da extração da } \\
\text { madeira no município, atuação } \\
\text { da Cooperativa Florestal e } \\
\text { legislação da época. } \\
\text { Relacionar o desmatamento } \\
\text { ocorrido com o crescimento do } \\
\text { município, custos ambientais e } \\
\text { ações de conservação } \\
\text { realizadas. }\end{array}$ & $\begin{array}{l}\text { Pesquisa: } \\
\text { Bibliografia, } \\
\text { jornais, legislação } \\
\text { e história oral. } \\
\\
\text { Bens naturais e } \\
\text { culturais e } \\
\text { recursos } \\
\text { didáticos: } \\
\text { araucárias } \\
\text { plantadas muito } \\
\text { próximas e pouco } \\
\text { desenvolvidas, } \\
\text { folheto } \\
\text { informativo e } \\
\text { mapa. }\end{array}$ \\
\hline
\end{tabular}


...continuação.

\begin{tabular}{|c|c|c|c|c|c|}
\hline Ponto & Descrição & Nome & Objetivo & Metodologia & $\begin{array}{l}\text { Subsídios } \\
\text { utilizados }\end{array}$ \\
\hline 6 & $\begin{array}{l}\text { Área com } \\
\text { Pinus e } \\
\text { eucalipto }\end{array}$ & $\begin{array}{c}\text { Floresta } \\
\text { Municipal? }\end{array}$ & $\begin{array}{l}\text { Comparar a } \\
\text { vegetação } \\
\text { nativa e } \\
\text { exótica e } \\
\text { informar sobre } \\
\text { a origem da } \\
\text { vegetação } \\
\text { exótica no } \\
\text { parque. }\end{array}$ & $\begin{array}{l}\text { Levar os participantes até o } \\
\text { ponto e pedir o que eles } \\
\text { percebem de diferenças entre } \\
\text { a vegetação nativa e exótica. } \\
\text { Explicar que a área tem } \\
\text { floresta exótica, pois os } \\
\text { responsáveis pelo parque } \\
\text { tinham objetivos extrativistas. } \\
\text { Fazer com que reflitam sobre } \\
\text { o que isto implica em relação } \\
\text { às diretrizes e normas das } \\
\text { UCs de proteção integral. } \\
\text { Contar que havia proposta de } \\
\text { categorização na forma de } \\
\text { Floresta Municipal na década } \\
\text { de } 1980 \text {. }\end{array}$ & $\begin{array}{l}\text { Pesquisa: } \\
\text { Jornais, } \\
\text { legislação, } \\
\text { bibliografia e } \\
\text { história oral. } \\
\\
\text { Bens naturais e } \\
\text { culturais e } \\
\text { recursos } \\
\text { didáticos: } \\
\text { Plantio de Pinus e } \\
\text { eucalipto, folheto } \\
\text { informativo e } \\
\text { mapa. }\end{array}$ \\
\hline 7 & Açudes & $\begin{array}{c}\text { Reconectar } \\
\text { com a } \\
\text { natureza }\end{array}$ & $\begin{array}{c}\text { Falar sobre os } \\
\text { objetivos de } \\
\text { uma área } \\
\text { protegida da } \\
\text { categoria } \\
\text { Parque } \\
\text { Natural } \\
\text { Municipal e } \\
\text { sobre as } \\
\text { atividades que } \\
\text { ocorreram ao } \\
\text { longo do } \\
\text { tempo na UC. }\end{array}$ & $\begin{array}{l}\text { Ir até a beira do açude e pedir } \\
\text { para que contemplem o local. } \\
\text { Questionar se os participantes } \\
\text { sabem quais são os objetivos } \\
\text { de uma área protegida da } \\
\text { categoria Parque. Relatar as } \\
\text { formas de uso não } \\
\text { condizentes com a } \\
\text { conservação da natureza que } \\
\text { ocorreram ao longo do tempo. } \\
\text { Comentar sobre o Clube } \\
\text { Carazinho de Tiro e Caça, } \\
\text { Associação de Funcionários } \\
\text { da Caixa Econômica Estadual, } \\
\text { pista de Motocross, Centro de } \\
\text { Dependentes Químicos e } \\
\text { demais formas de uso } \\
\text { irregular. Relatar a importância } \\
\text { do envolvimento da AMA, por } \\
\text { meio do Projeto Charão, na } \\
\text { defesa da área. Informar sobre } \\
\text { as atividades de educação e } \\
\text { interpretação ambiental } \\
\text { desenvolvidas atualmente. }\end{array}$ & $\begin{array}{c}\text { Pesquisa: } \\
\text { História oral, } \\
\text { jornais, legislação } \\
\text { e bibliografia. } \\
\\
\text { Bens naturais e } \\
\text { culturais e } \\
\text { recursos } \\
\text { didáticos: } \\
\text { Reservatórios } \\
\text { artificiais, folheto } \\
\text { informativo e } \\
\text { mapa. }\end{array}$ \\
\hline 8 & Nascente & $\begin{array}{c}\text { O berço da } \\
\text { vida }\end{array}$ & $\begin{array}{c}\text { Explicar a } \\
\text { importância da } \\
\text { contribuição } \\
\text { da área } \\
\text { protegida para } \\
\text { a manutenção } \\
\text { da qualidade e } \\
\text { quantidade de } \\
\text { água do Rio } \\
\text { da Várzea. }\end{array}$ & $\begin{array}{l}\text { Levar os participantes até o } \\
\text { local, pois a água da nascente } \\
\text { desemboca no ponto de } \\
\text { captação do município. } \\
\text { Relacionar a qualidade e a } \\
\text { quantidade de água com a } \\
\text { manutenção das matas } \\
\text { ciliares. Importância da água } \\
\text { para as questões econômicas, } \\
\text { sociais, ambientais e } \\
\text { espirituais da sociedade. }\end{array}$ & $\begin{array}{c}\text { Bens naturais e } \\
\text { culturais e } \\
\text { recursos } \\
\text { didáticos: } \\
\text { Nascente, folheto } \\
\text { informativo e } \\
\text { mapa. }\end{array}$ \\
\hline
\end{tabular}

Continua... 
...continuação.

\begin{tabular}{|c|c|c|c|c|c|}
\hline Ponto & Descrição & Nome & Objetivo & Metodologia & $\begin{array}{l}\text { Subsídios } \\
\text { utilizados }\end{array}$ \\
\hline 9 & Bica & $\begin{array}{l}\text { Pensando } \\
\text { nas futuras } \\
\text { gerações. }\end{array}$ & $\begin{array}{c}\text { Refletir sobre } \\
\text { a importância } \\
\text { da área } \\
\text { protegida } \\
\text { como } \\
\text { patrimônio } \\
\text { ambiental e } \\
\text { realizar a } \\
\text { avaliação da } \\
\text { atividade. }\end{array}$ & $\begin{array}{l}\text { Pedir como se sentem ao final } \\
\text { da trilha e que compartilhem } \\
\text { suas percepções sobre o } \\
\text { Parque. Salientar que, ao final } \\
\text { da trilha, percebemos que a } \\
\text { paisagem contém elementos } \\
\text { que "contam" a história da } \\
\text { área protegida. Falar sobre a } \\
\text { regularização do cadastro } \\
\text { junto ao Sistema Estadual de } \\
\text { Unidades de Conservação. } \\
\text { Neste ponto, é declamada } \\
\text { uma poesia sobre o parque, } \\
\text { escrita por Waner Sanches } \\
\text { Barreto, um dos entrevistados } \\
\text { nessa pesquisa. Um } \\
\text { questionário para avaliação da } \\
\text { atividade é aplicado e os } \\
\text { participantes são convidados } \\
\text { para um banho na bica. }\end{array}$ & $\begin{array}{l}\text { Pesquisa: } \\
\text { Bibliografia, } \\
\text { legislação. } \\
\\
\text { Bens Naturais e } \\
\text { culturais e } \\
\text { recursos } \\
\text { didáticos: } \\
\text { Bica, poesia } \\
\text { construída por um } \\
\text { dos } \\
\text { entrevistados, } \\
\text { folheto } \\
\text { informativo e } \\
\text { mapa. }\end{array}$ \\
\hline
\end{tabular}

Fonte: Autoria própria.

Dos nove pontos interpretativos propostos, somente dois não foram embasados nos testemunhos orais. O ponto 8 , "O berço da vida", foi inserido pela importância da contribuição do PNMJ em relação às suas nascentes, pois elas colaboram com o curso hídrico onde é realizada a captação de água para abastecimento do município. No último ponto, não foi utilizada a história, mas há colaboração de um dos entrevistados na forma de uma poesia.

\section{Resultados do teste piloto}

Foram organizados grupos pequenos para a testagem da trilha interpretativa guiada (Figura 2). Trinta e seis indivíduos preencheram os questionários de avaliação. Dentre eles, dez professores, um vereador, dois diretores de Departamentos Municipais - de Meio Ambiente e de Trânsito, um Secretário Municipal Geral do Governo, uma Secretária Municipal de Assistência Social, o Gestor do PNMJ, duas representantes da imprensa, dois advogados, duas funcionárias públicas, um engenheiro, uma biomédica, uma designer, um profissional autônomo da área ambiental, um eletricista, uma estudante universitária, um agente de cultura e lazer e cinco idosos do grupo Maturidade Ativa do Serviço Social do Comércio do Rio Grande do Sul (SESC Carazinho). Dois indivíduos não mencionaram a sua profissão. Quatro dos entrevistados desta pesquisa participaram também do teste piloto.

Quanto ao gênero, participaram 26 mulheres e 10 homens. Em relação ao nível de instrução, 02 possuem ensino fundamental incompleto, 10 possuem ensino médio completo, 10 possuem ensino superior e 15 possuem pósgraduação. Dentre eles, 05 estavam visitando o parque pela primeira vez, 18 
vão à área protegida por até três vezes ao ano, 05 visitam de quatro a dez vezes ao ano e 07 frequentam o local mais de dez vezes ao ano.

Entre os participantes, 28 costumam ter momentos de lazer junto à natureza e 08 não costumam ter, 35 participantes relataram que o grau de satisfação de realizar a trilha foi excelente e um que foi bom. Todos gostaram da experiência da trilha interpretativa e relataram ter adquirido conhecimento por meio das informações compartilhadas no percurso. Em relação aos conhecimentos adquiridos, foi destacada a história ambiental do município, a história do Parque, a importância da conservação ambiental para as gerações presentes e futuras, o período da extração madeireira no município e o "reflorestamento" efetuado, a importância das nascentes, das árvores frutíferas e das matas ciliares. Foi salientado o conhecimento sobre espécies vegetais nativas e exóticas, especialmente sobre a araucária, a legislação ambiental e relacionada ao Parque, considerações sobre o manejo das espécies exóticas, envolvimento da sociedade e de personalidades que fizeram parte da história do PNMJ.

Neste contexto, Ikemoto et al. (2009, p. 285) alertam que se deve levar em consideração que, na realização de uma trilha interpretativa, o guia não pode limitar-se a transmitir informações sobre os bens naturais. Os aspectos históricos e culturais são importantes para que os ouvintes relacionem os conteúdos abordados com o seu dia a dia e com sua história pessoal.

Em relação às funções do PNMJ, os participantes acreditam que as áreas protegidas são importantes para o lazer e desenvolvimento de ações educativas. Destacaram-se a realização de atividades práticas, o contato com a natureza e a utilização, das mesmas, como recurso para a aprendizagem das crianças e adolescentes, pois o Parque possui diferentes atributos naturais. Pode-se desfrutar de momentos de relaxamento, aliviando o estresse do cotidiano, fugir do contato excessivo com recursos tecnológicos. Foi salientada a importância da mediação do conhecimento pela guia e a possibilidade de maior participação da sociedade nestes locais.

Conforme uma das participantes, "temos um laboratório a céu aberto e precisamos valorizar a nossa história". Por meio das atividades educativas e de lazer pode-se sensibilizar para o cuidado com a natureza e dar valor à vida das diversas espécies. Destacou-se que o PNMJ é um local de integração entre diferentes segmentos sociais. As atividades desenvolvidas permitem a apropriação do conhecimento e propiciam a identificação e o sentimento de pertencimento dos sujeitos em relação à própria história. Leva a refletir sobre a vida e a natureza e sobre a continuidade destas áreas para as futuras gerações. Conforme outra participante, o local "conecta o ser humano a sua essência".

Todos os participantes acreditam que o PNMJ tem potencial para auxiliar na valorização da história do município. Alguns se manifestaram dizendo que o local é pouco aproveitado e que contém histórias que não podem ser esquecidas. O parque é visto como ideal para a realização de atividades em

revista brasileira educação ambiental 
família, pois traz tranquilidade e paz. A área acolheu uma das participantes em momentos difíceis, como espaço de meditação. Destacou-se a beleza cênica, a diversidade de ambientes e a importância cultural para o município. Contudo, a falta de segurança para a realização das atividades também foi mencionada. Uma participante destacou que o local estava esquecido, mas que aos poucos está começando a receber a devida atenção. Outra participante salientou que o parque apresenta potencial para ser referência se houvesse investimento e maior cuidado por parte do poder público. Para outra participante, faltam atividades e políticas públicas com continuidade e consistentes.

Conforme Lima-Guimarães (2010, p. 8), o aprendizado proporcionado por meio da experiência nas trilhas interpretativas e vivências no ambiente natural são interações de genuína imersão, nas quais percebem-se respostas sensoriais e afetivas intensas, ao tempo em que a paisagem é entendida como fonte de aprendizagem dirigida e incidental sobre uma visão ecológica planetária. Estas atividades colaboram positivamente e efetivamente com ações de conservação da natureza, pois as trilhas e vivências no ambiente natural proporcionam cooperação, socialização, interação e o entendimento entre as formas de conhecimento empírico, técnico e científico e saberes tradicionais. Oportunizam novas mediações e inter-relações entre as populações.

Como sugestão para a trilha interpretativa destacou-se a melhoria da infraestrutura e sugeriu-se o acompanhamento de alguma pessoa que viveu períodos relevantes da história do PNMJ. Conforme um participante poderiam ser apresentadas fotos históricas dos períodos mencionados nas estações. Salientou-se a importância de a trilha ocorrer com mais frequência e de continuar a atividade. Sugeriu-se que deve ser mais divulgada e que seria interessante um folheto educativo na forma de mapa. Também se destacou a necessidade de suporte para o transporte até o local, por meio do governo municipal. Dois idosos mencionaram que seria importante solicitar aos participantes que trouxessem sacolas para o recolhimento de resíduos que podem ser encontrados durante o percurso.

A trilha não foi aplicada para deficientes físicos. Contudo, duas pessoas que estavam com problemas de mobilidade conseguiram realizar a trilha sem maiores dificuldades.

Após o desenvolvimento do teste piloto, a trilha interpretativa, "Nosso Parque, nossa história: da extração madeireira à conservação ambiental", passou a integrar o Programa de uso público, "Conhecer para preservar", desenvolvido pela gestão do PNMJ e Departamento Municipal de Meio Ambiente.

Atualmente, três trilhas interpretativas integram o programa de uso público do PNMJ. A trilha foi uma das atividades de Educação Ambiental aplicadas durante o "Il Domingo no Parque" (Figura 3), o qual foi promovido com o intuito de reconectar a população com a área protegida. Neste mesmo 
dia foram desenvolvidas outras atividades educativas e de recreação por um grupo de parceiros do parque.
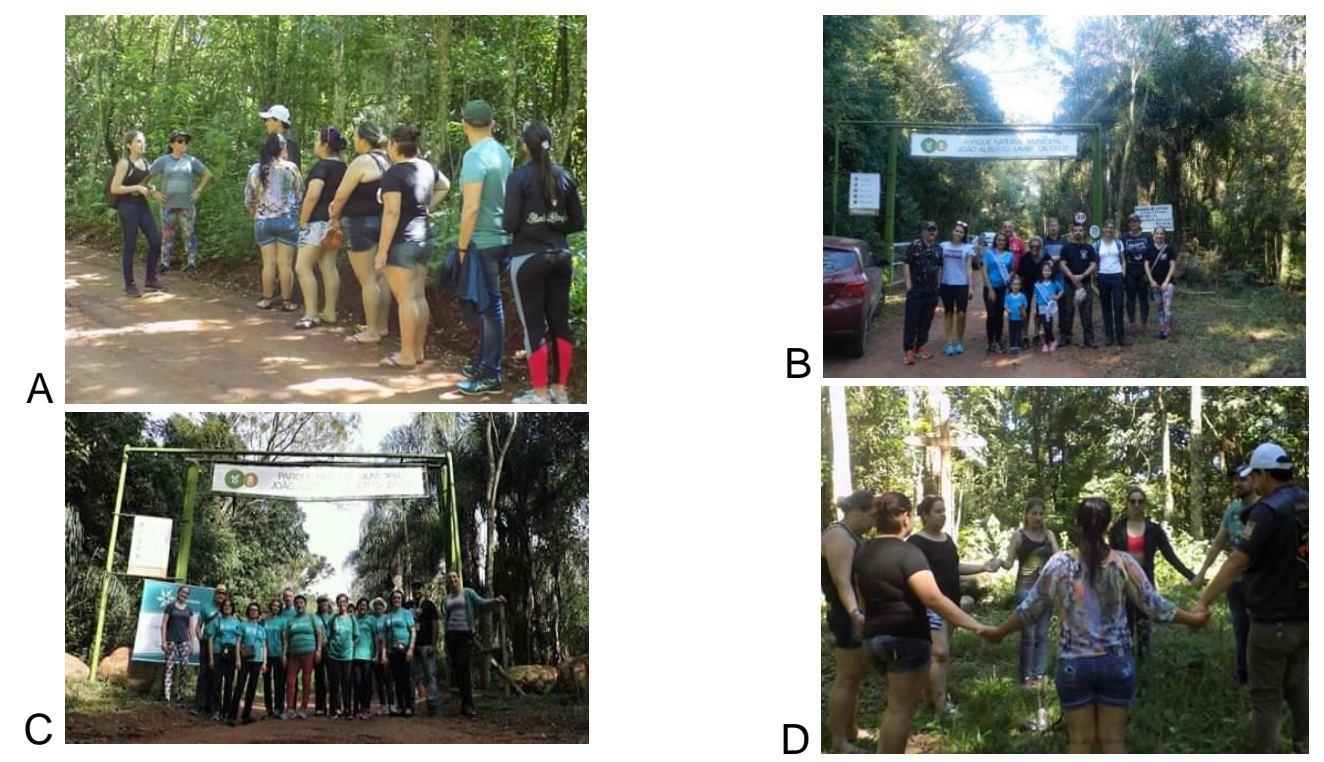

Figura 2: Grupos participando da trilha Interpretativa guiada. A: Grupo heterogêneo. B: Grupo de gestores e imprensa. C: Grupo de idosos. D: Ponto interpretativo "A árvore sagrada". Fonte: Autoria própria.

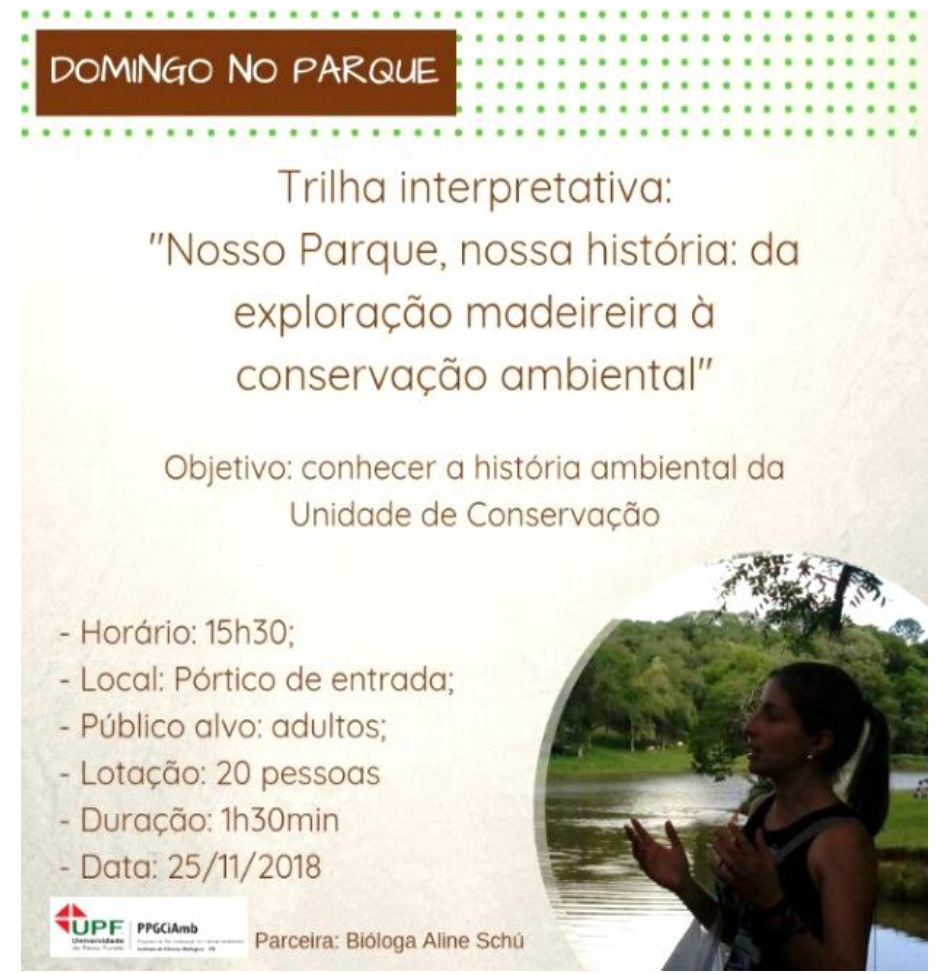

Figura 3: Divulgação da trilha interpretativa guiada como atividade no "Il Domingo no Parque". Fonte: Departamento Municipal de Meio Ambiente (DEMA). 
Quando a sociedade é convidada a participar do planejamento de uma atividade para uma área pública, ela pode tomar consciência da importância de seu envolvimento de forma coletiva e individual. Segundo Varine (1987, p. 101),

é na ação que uma comunidade se forja e se faz reconhecer como força política e entidade social de forma total. É na ação que ela adquire características próprias, que ela existe. Ela é porque age, e cada um de seus membros, participando de uma tal ação, fará a prova e tomará a consciência de sua capacidade autônoma de pensar e de ser. Assim, apoiando-se uma sobre a outra, comunidade e indivíduo afinarão progressivamente sua experiência, seu conhecimento dos obstáculos e dos meios, a expressão dos objetivos e dos métodos. Enfim, para o adversário, para os poderes estabelecidos hostis à mudança e à redução dos privilégios adquiridos ou herdados, para tudo aquilo que se opõe ao desenvolvimento e à criação do homem pelo homem, a ação comunitária será a prova da existência de um desafio e assim, talvez, para os melhores responsáveis, para os mais lúcidos entre eles, o estímulo para uma nova política, para a mudança.

A trilha interpretativa guiada foi utilizada como método de sensibilização e de educação patrimonial. De acordo com a Política de Patrimônio Cultural Material do Instituto do Patrimônio Histórico e Artístico Nacional, a educação patrimonial compreende os processos educativos formais e não formais, que foram elaborados de forma coletiva e com abordagem dialógica, tendo como objetivo o Patrimônio Cultural socialmente apropriado tomado como fonte para compreensão social e histórica das referências culturais, com o intuito de sua preservação (BRASIL, 2018).

Neste sentido, Varine (2013, p. 137) afirma que a educação patrimonial é uma ação global, destinada a uma população e ao seu território, que se utiliza de instituições, mas sem se identificar com qualquer uma delas em específico. Tem como objetivo o desenvolvimento local e não somente a aquisição de conhecimentos sobre o patrimônio ou uma animação cultural. A ideia é levar o maior número possível de pessoas a conhecer e a utilizar o patrimônio comum dessa comunidade.

Durante a realização do percurso da trilha interpretativa, alguns participantes relataram não conhecer a história do PNMJ e, ao final da atividade, o parque foi visto como patrimônio histórico e ambiental do município. 


\section{Conclusão}

A importância da trilha interpretativa guiada para a aquisição de conhecimentos, como ferramenta educativa e de sensibilização ambiental e para a valorização do parque, foi reconhecida pelos participantes do teste piloto. A inclusão da trilha no Programa de Uso Público demonstra que a gestão municipal de Carazinho valorizou a proposta criada em colaboração com a sociedade.

Inserir algumas informações provenientes da pesquisa em História Oral na trilha foi importante, pois conta parte das vivências de algumas pessoas em relação à área protegida. Vivências que foram lembradas e contadas, o que pode valorizar a memória local e o envolvimento da sociedade com estes espaços.

As trilhas interpretativas são ferramentas que podem ser utilizadas para a reconexão das pessoas com as áreas protegidas. Ao envolver a sociedade na construção de propostas de interpretação ambiental fortalecem-se os sentimentos de identidade e pertencimento.

Utilizar uma trilha interpretativa guiada como metodologia de educação patrimonial tende a auxiliar a sensibilização da população, ampliando o reconhecimento da importância do PNMJ como patrimônio ambiental e histórico a ser resguardado. Sugere-se que a educação patrimonial seja incluída como política pública por parte do governo municipal.

\section{Referências e Fontes}

BRASIL. Decreto Legislativo no 2, de 05 de junho de 1992. Convenção Sobre Diversidade Biológica. Disponível em: <http://www.mma.gov.br/estruturas/sbf chm rbbio/ arquivos/cdbport 72.pdf>. Acesso em: 26 nov. 2017.

BRASIL. Diretrizes para visitação em Unidades de Conservação. Ministério do Meio Ambiente. Secretaria de Biodiversidade e Florestas. Departamento de Áreas Protegidas. Brasília, 2007. Disponível em: $<$ https://www.mma.gov.br/estruturas/ascom boletins/ arquivos/livro.pdf>. Acesso em: 08 jan. 2020.

BRASIL. Portaria no 375, de 19 de setembro de 2018. Institui a Política de Patrimônio Cultural Material do Iphan e dá outras providências. Disponível em: $<$ http://www.in.gov.br/web/dou/-/portaria-n-375-de-19-de-setembro-de-201841601031>. Acesso em: 14 out. 2019.

GERHARDT, M.; NODARI, E.S. Patrimônio ambiental, História e biodiversidade. Fronteiras: Journal of Social, Technological and Environmental Science, Anápolis, v.5, n.3, p.54-71, jul./dez. 2016.

HÜNING, C. Entrevista concedida a Aline Schú. Carazinho, 23 jul. 2018. [A entrevista encontra-se gravada no acervo da autora]. 
IBGE. Instituto Brasileiro de Geografia e Estatística. Mapa da área de aplicação da Lei 11.428 de 2006. 2012. Escala: 1:5.000.000. Disponível em:

$<$ http://geoftp.ibge.gov.br/informacoes ambientais/estudos ambientais/biomas/ mapas/lei11428 mata atlantica.pdf>.Acesso em: 14 abr. 2020.

IKEMOTO, S.M. et al. Avaliação do potencial interpretativo da trilha do jequitibá, Parque Estadual dos Três Picos, Rio de Janeiro. Sociedade \& Natureza. Uberlândia. 21 (3): 271-287, 2009.

KUSSLER, A.L. Entrevista concedida a Aline Schú. Carazinho, 23 jul. 2018. [A entrevista encontra-se gravada no acervo da autora].

LIMA-GUIMARÃES, S.T.Trilhas Interpretativas e Vivências na natureza: aspectos relacionados à percepção e interpretação da paisagem. Caderno de Geografia. v. 20. n. 33. 2010.

LOPES, M.R.O. Entrevista concedida a Aline Schú. Carazinho, 13 mar. 2019. [A entrevista encontra-se gravada no acervo da autora].

LUZ, S.R.D. Entrevista concedida a Aline Schú. Carazinho, 15 jan. 2019. [A entrevista encontra-se gravada no acervo da autora].

MARTINEZ, J. et al. A trilha interpretativa como recurso didático na Educação Básica. In: STURM, Luciane et al (Org.). Qualidade do Ensino na Educação Básica: Contribuições das ciências da natureza, da matemática e de suas tecnologias. Passo Fundo: Upf, 2015. 272 p.

MEDEIROS, R. Evolução das tipologias e categorias de áreas naturais protegidas no Brasil. Ambiente \& Sociedade, São Paulo, v.IX, n. 1, p.40-64, jun. 2006.

PÁDUA, J.A. As bases teóricas da História Ambiental. Estudos Avançados, São Paulo, v. 24, n. 68, 2010.

PRESTES, N.P. Entrevista concedida a Aline Schú. Carazinho, 29 maio, 2019. [A entrevista encontra-se gravada no acervo da autora].

ROVAI, M.G.O. Tradição oral e patrimônio imaterial: o papel da memória na luta por políticas públicas na Comunidade de Canárias, Maranhão. Revista Resgate. Vol. XXI, p. 7-16, 2013.

SNUC. Sistema Nacional de Unidades de Conservação da Natureza. Lei n. 9.985, de 18 de julho de 2000. Brasília: MMA/SBF, 2000, (32 p.) Disponível em: $<$ http://www.planalto.gov.br/ccivil 03/leis/L9985.htm>. Acesso em: 26 nov. 2017.

SUCKAU, V.A. Entrevista concedida a Aline Schú. Carazinho, 02 ago. 2018. [A entrevista encontra-se gravada no acervo da autora]. 
TILDEN, F. Interpreting our heritage. North Carolina: The University of North Carolina Press, $1977 . \quad$ Disponível em: $<$ https://is.muni.cz/el/1421/podzim2017/MUI 338/Interpreting Our Heritage C hapel Hill Books .pdf >. Acesso em: 08 jan. 2020.

TOLEDO, S.S. Entrevista concedida a Aline Schú. Carazinho, 09 jan. 2019. [A entrevista encontra-se gravada no acervo da autora].

VARINE, H. O tempo social. Tradução Fernanda Camargo-Moro e Lourdes Rego Novaes. Rio de Janeiro: Eça Editora, 1987.

VARINE, $H$. As raízes do futuro - O patrimônio a serviço do desenvolvimento local. Tradução Maria de Lourdes Parreiras Horta. Porto Alegre: Medianiz, 2013.

VASCONCELLOS, J.M.O. Avaliação da visitação pública e da eficiência de diferentes tipos de trilhas interpretativas no Parque Estadual Pico do Marumbi e Reserva Natural Salto Morato - PR. 1998. 163 f. Tese (Doutorado em Engenharia Florestal), Curso de Pós-Graduação em Engenharia Florestal, Universidade Federal do Paraná, Curitiba, 1998. Disponível em: <https://acervodigital.ufpr.br/handle/1884/25417>. Acesso em: 08 jan. 2020.

VASCONCELLOS, J.M.O Trilhas interpretativas: aliando educação e recreação. In: CONGRESSO BRASILEIRO DE UNIDADES DE CONSERVAÇÃO. Anais. Curitiba: UNILIVRE. v.1. p. 465-477, 1997.

VIDAL, P.G. Entrevista concedida a Aline Schú. Carazinho, 30 jan. 2019. [A entrevista encontra-se gravada no acervo da autora]. 